\title{
ASSESSMENT OF BUILDING RESPONSE TO LIQUEFACTION- INDUCED DIFFERENTIAL GROUND DEFORMATION
}

\author{
Juliet F. Bird ${ }^{1}$, Helen Crowley ${ }^{2}$, Rui Pinho², Julian J. Bommer ${ }^{3}$
}

\begin{abstract}
The occurrence of liquefaction during earthquakes can cause significant damage to buildings and infrastructure. The damaging effect of liquefaction is a permanent deformation of the ground, which will either be vertical in level ground, or horizontal (with a vertical component) in sloping ground or in the vicinity of a free face. Buildings in zones of liquefaction are particularly vulnerable to differential ground movements, resulting from the heterogeneity of stratigraphy and soil properties.

Many published methodologies are now available for assessing the likelihood and extent of liquefaction occurrence. However, it is equally important to understand how the occurrence of liquefaction will affect the built environment. This paper presents analytical solutions for the assessment of expected structural damage to existing reinforced concrete frame buildings resulting from liquefaction-induced differential ground movements. The methodology is primarily intended for application to assessments of expected earthquake damage and losses to existing buildings, and therefore satisfies the requirements of such studies for a simple, rational approach using easily attainable structural parameters to represent the building stock.
\end{abstract}

Key Words: Liquefaction, permanent ground deformation, building damage, fragility curves, earthquake loss estimations.

\section{INTRODUCTION}

Methodologies for the assessment of liquefaction potential and the resulting ground deformation have been the focus of research for many years, since the two catastrophic earthquakes in Niigata, Japan, and Alaska in 1964 raised awareness of the damaging potential of widespread ground failure. The determination of the impact that liquefactioninduced deformations will have on existing structures, however, remains a 'grey' area in research and practice. There are many reasons for this, not least being that the preferred design approach is to mitigate the liquefaction risk by ground improvement or site re-location. Typically, a structural engineer will determine the deformation tolerances for a structure, and the geotechnical engineer will ensure through design that these criteria are satisfied.

The problem of building damage caused by liquefaction has been approached herein from the perspective of earthquake loss estimations. These require a pragmatic solution to the issues of spatial uncertainty and variability in ground conditions and the exposed building stock, while still

1 Arup Geotechnics, The Arup Campus, Blythe Gate, Blythe Valley Park, Solihull, West Midlands B90 8AE, UK

2 European School for Advanced Studies in Reduction of Seismic Risk (ROSE School), clo EUCENTRE, Via Ferrata 1, Pavia, Italy.

3 Department of Civil and Environmental Engineering, Imperial College London, UK. 
producing a realistic and meaningful estimation of the expected damage distribution as a result of earthquake hazards. Two significant features of earthquake loss estimations from an engineering perspective are their regional nature and the fact that they deal with existing buildings and infrastructure, about which very little may be known. Both of these features present a considerable contrast to site-specific design. In the assessment of existing buildings rather than the design of new ones, avoidance of ground deformation hazards is not an option and therefore a method is required to estimate the magnitude and direction of the ground deformation and the resulting structural damage.

The procedure presented in this paper is particularly suitable for the assessment of earthquake related damage, due in part to its compatibility with the procedure for the estimation of earthquake damage caused by ground shaking from which it was developed (Crowley et al., 2004). However, its application is equally valid for non-earthquake related causes of significant vertical or horizontal ground deformations affecting a geographically distributed collection of buildings.

Elements from earthquake loss estimations which have particular relevance in this study include:

- The need to group buildings into different classes with broadly similar behaviour;

- the importance of modelling the actual behaviour of existing buildings as opposed to the design behaviour of new buildings, according to modern seismic design practice,

- the use of relationships between demand and capacity to estimate damage levels at any given demand, and

- the use of damage states to characterise the results.

Advanced numerical modelling techniques used in sitespecific design to assess the interaction of the liquefied soil and overlying structures cannot be employed in this context, both because the demands of time and data acquisition would be prohibitive, and because the degree of accuracy in the input data is not commensurate with such approaches. It must be accepted in a regional study that individual buildings have to be grouped into classes, as do similar ground conditions, and there is therefore a high degree of approximation associated with the parameters selected to represent each group.

\section{2.}

\section{BUILDING RESPONSE TO DIFFERENTIAL GROUND DEFORMATIONS}

\subsection{Liquefaction-induced ground deformations}

As noted by Vanmarcke (1977), and Fenton and Vanmarcke (1998) it is the maxima and minima within a soil profile that can control geotechnical performance, and therefore consideration of average properties, and the average (uniform) deformations that these yield, is insufficient for damage estimation requirements. The differential component of liquefaction-induced ground deformations can cause the greatest damage to buildings.

In the event of earthquake-induced liquefaction at a level site, differential ground settlements would occur due to heterogeneity in soil stiffness and spatial variability. Differential settlements may also occur due to asymmetric foundation loads, or localised features such as ground loss due to sand boils. At sloping sites, or near to free faces, differential lateral movements would also be caused by the variability of in situ ground conditions; however, these would also have a less random component related to geometric variability in terms of increasing distance from a free face or from the toe of a slope.

In order to capture the uncertainties associated with defining liquefaction-induced permanent ground deformations on a regional basis, a probabilistic approach is required. These uncertainties are both epistemic (i.e. related to lack of knowledge) such as the selection and potential inaccuracy of the calculation approach to predict the ground deformations, or the extrapolation of limited geotechnical data to cover large areas, and aleatory (i.e. random), such as the natural variability in geology and topography. The distinction between the two types of uncertainty is important since the first can be reduced with sufficient research and analysis whereas the second cannot. A further uncertainty arises from the fact that local ground conditions must be grouped into zones with broadly similar properties and topography. For convenience, this simplification is treated as an aleatory uncertainty, since to reduce it would require many different site classifications to be used, which is counter to the 
requirements of a loss model. In this model, for differential ground movements, the demand is therefore quantified in terms of the median value of expected differential settlements and/or differential lateral movements, with a standard deviation and an assigned statistical distribution.

\section{$2.2 \quad$ Building classifications}

Regional damage estimation methodologies generally classify the existing building stock according to the structural system, building materials, height and level of seismic design (a function of age, and the quality and quantity of local building codes). Such classifications are in most cases sufficient for the estimation of building response to earthquake-induced ground shaking. When ground deformations are considered, either in addition to or instead of earthquake ground shaking, the foundation system will also influence a building's response, and must be considered in the building classification. The height is not a critical variable for the response to ground deformations, unlike for ground shaking, but for compatibility, the same classifications are used for both causes of damage. As with site conditions, it is necessary to group buildings with similar behaviour under earthquake loading, to enable a regional assessment to be undertaken.

In the procedures presented in this paper, $\mathrm{RC}$ frame buildings (without infill walls), with pad or strip footings are considered. This single building class is then subdivided into different height ranges (for ground shaking response), and into two levels of seismic design, poor and good. For RC frame buildings, the latter classification depends upon the level of confinement and the consequent failure mode due to ground shaking, where poor buildings have a higher probability of soft-storey (column sway) failure. Finally, consideration must be given to the geometric and material properties of a given group of buildings (e.g. RC frame, pad footings, mid-rise, poor seismic design), which will influence their capacity to resist earthquake damage. In this paper these variables are represented in a probabilistic framework, such that the capacity is assigned a statistical distribution, which will be a function of the uncertainty associated with the geometric and material properties.

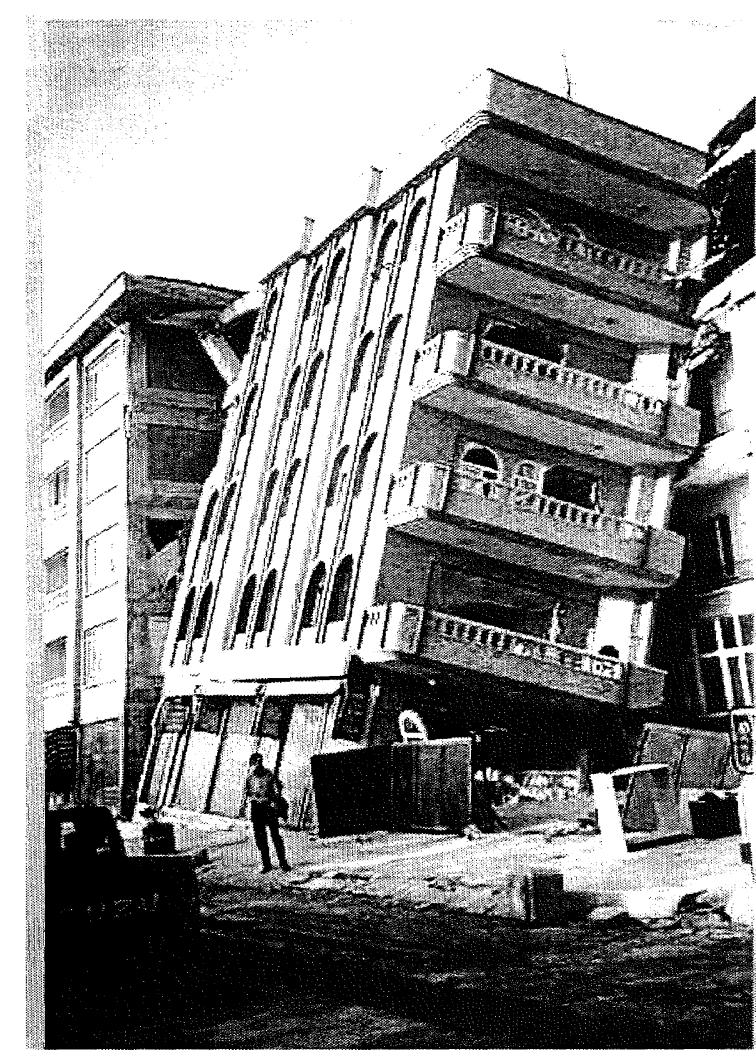

Figure 1a: Rigid body response of buildings with stiff shallow foundations to earthquake-induced liquefaction following the August 171999 Kocaeli earthquake in Turkey (courtesy Earthquake Engineering Field Investigation Team, UK).

Building deformations

The evaluation of building vulnerability to liquefactioninduced ground deformations is less straightforward than for ground shaking, which is mainly due to inter-storey drift, because of the variety of ways in which buildings can respond. Structural response to ground movements at foundation level will either be to displace as a rigid body, if the foundations have sufficient relative stiffness compared to the soil (Fig. la) or if the ground deformations are uniform, or else to deform structurally if there is a sufficient lack of restraint between foundations for the walls or columns to move independently, and thus differentially (Fig. Ib). Both Fig. $1 \mathrm{a}$ and $\mathrm{lb}$ represent valid modes of building response to liquefaction, depending upon the type of foundations used in the affected area. This paper presents analytical solutions to 
the latter case, i.e. foundations which are unrestrained, or compliant, such as individual pad footings, or poorly- or unreinforced strip footings. Current seismic design practice (e.g. Eurocode 8, Part 5) recognises that footings should be connected with tie beams. Nonetheless, existing buildings in many seismically active parts of the world do not have good connections between individual footings, and it is in recognition of these cases that the procedure presented in this paper has been developed. For the former case of rigid-body building response (Fig. 1a), where the foundations comprise a raft or well-connected footings, there are no analytical solutions for the estimation of damage states and empirical solutions are required (Bird et al., 2006).

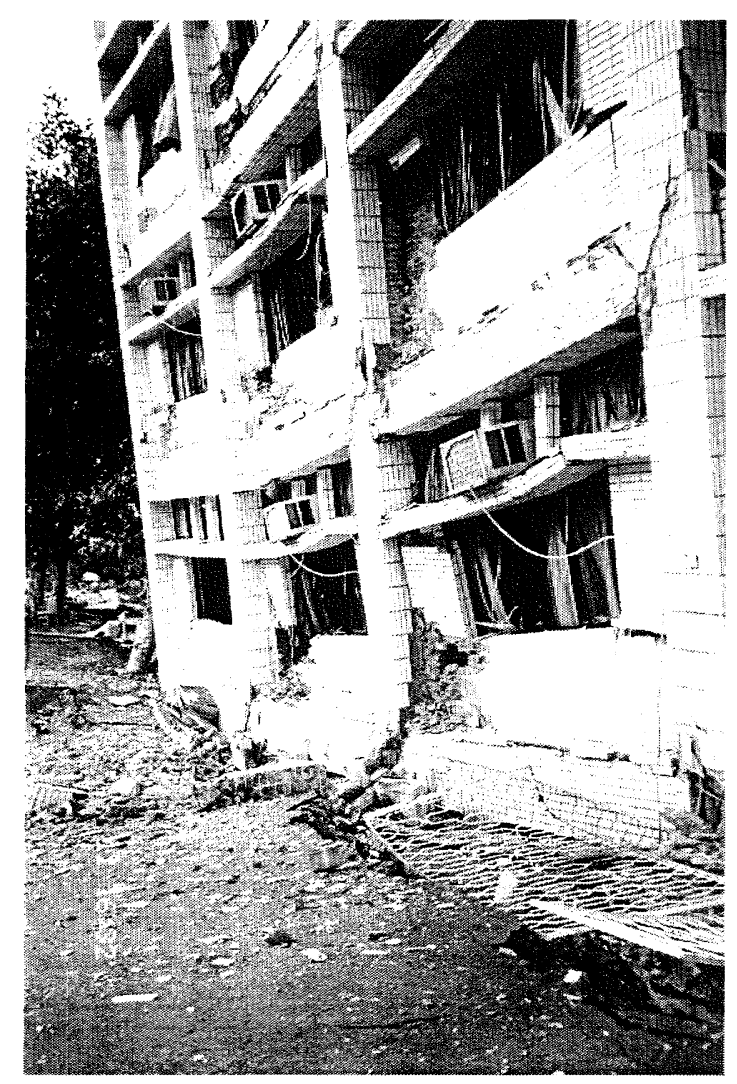

Figure 1b: Liquefaction induced damage of a technical school building after the 1999 Chi Chi earthquake. Courtesy Marshall Lew, Los Angeles Tall Buildings Structural Design Council.

The various complex ways in which ground deformations may impact on reinforced concrete frame buildings have been simplified to the four idealised cases shown in Figs. 2 to 5. The demand on the structural members is related to the magnitude of the differential deformations rather than the absolute values. The vertical deformation in level ground beneath a single-bayed frame, shown in Fig. 3, places the same deformational demand on the members as in a multibayed frame, and so this mechanism can also be used to represent the frame shown in Fig. 2.

The deformed shapes in Figs. 2 to 5 show that, providing P- $\Delta$ effects do not become significant, the building height is not critical in assessing building response due to ground failure, an observation confirmed analytically by Koutsourelakis et al. (2002). Figs. 2 to 4 demonstrate that the displacement demand is concentrated in the ground floor columns, whilst in Fig. 5 it is seen that the demand is equal in the beams of all storeys. It should be noted that Figs. 2 to 5 present illustrative deformed shapes only, and are not exhaustive, particularly as the number of bays and hence configurations increases. However, the most onerous demand on the structural members would in most cases be analogous to one of these cases; for example the demand on the beams in Fig. 5 could be caused by the outer footings settling more than the interior one.

The response of the RC frame buildings to applied displacement at foundation level was analysed in order to assess the deformation demand on the beams and columns. Analytical relationships for the capacity to such deformational demands have then been developed and are presented in the following sections. The analyses were carried out using SeismoStruct (SeismoSoft, 2005), a fibremodelling finite element program for seismic analysis of framed structures. The program is capable of predicting the large displacement behaviour of space frames under static or dynamic loading, taking into account both local (beamcolumn effects) and global (large displacements/rotations effects) geometric non-linearities as well as material inelasticity. The spread of the latter along the member length and across the section area is explicitly represented through the employment of a fibre modelling approach, used in the formulation of the inelastic beam-column frame elements. 


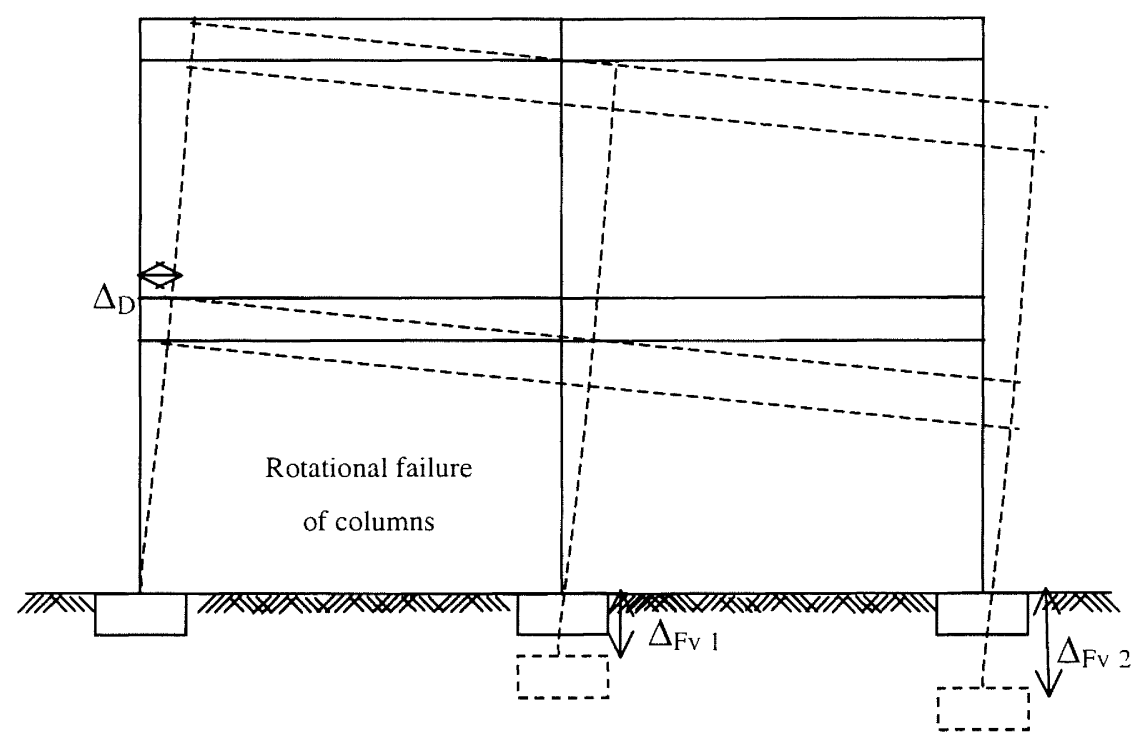

Figure 2: Idealised response of a multi-bayed RC frame building with unrestrained shallow foundations to differential vertical settlements, with approximately equal differential movements between each bay (not to scale).

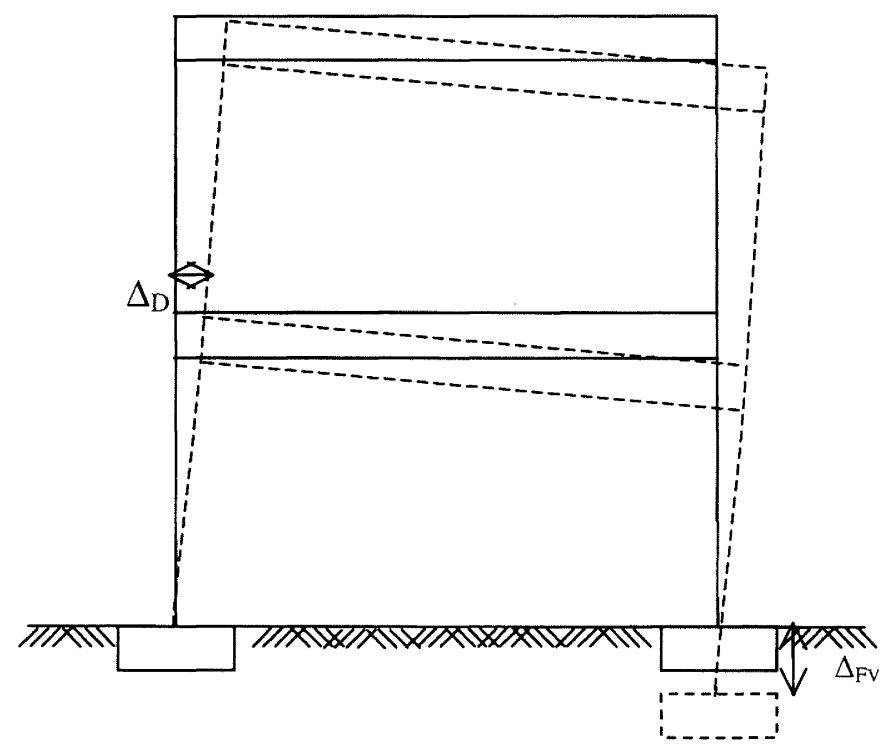

Figure 3: Idealised response of a single-bay RC frame building with unrestrained shallow foundations to differential vertical settlements (not to scale).

Parametric studies were carried out on the structural models to allow for variations in building geometry and level of foundation deformation, and it was seen that the deformed shapes were essentially the same irrespective of these variables. Significantly, the deformations take place in the columns rather than the beams for the single-bay cases. Furthermore, it is noted that the deformation is concentrated in the ground floor columns, with the higher storeys, irrespective of storey height or number of storeys, rotating as rigid bodies. In the case of vertical ground displacements, this occurs because the columns are free to rotate laterally and therefore behave as cantilevers in simple bending; the formation of plastic hinges at the base of the building is the simplest failure mechanism (Figs 2 and 3). Intuitively, one might expect the vertical deformation to be taken up by the beams, i.e. repeating the pattern at ground level in the upper 
floors, such as is shown in Fig. 5. However, when there is no restraint to keep the columns vertical (as there is in Fig. 5), the flexural stiffness of the beams is such that they do not deform but move laterally. The beams would have to be unrealistically flexible before a failure mechanism involving flexure of the beams would occur.

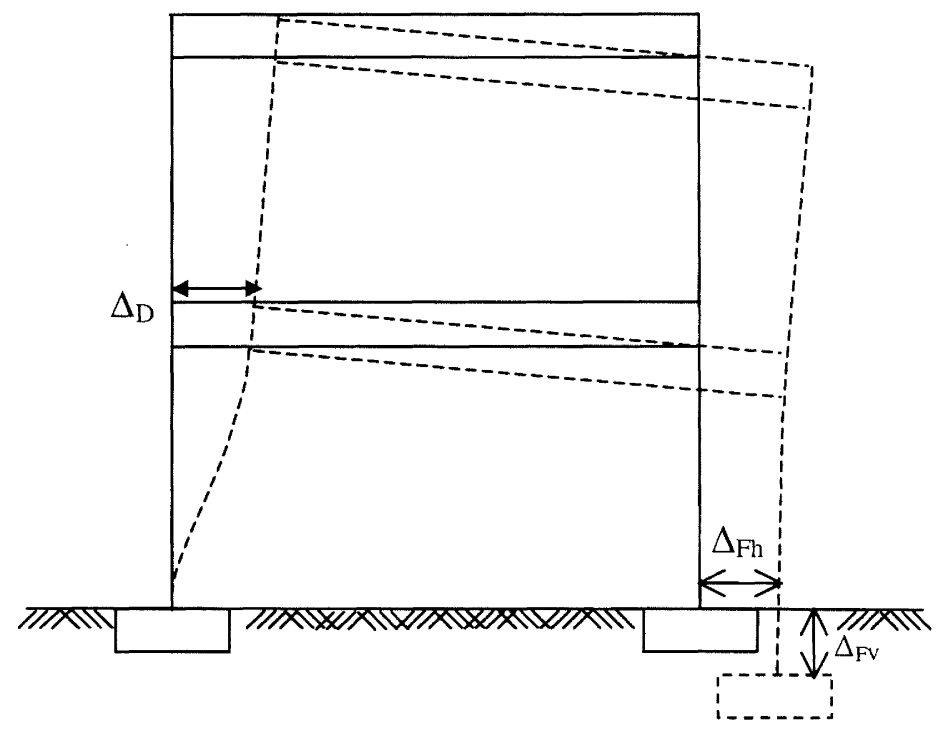

Figure 4: Idealised response of an RC frame building with unrestrained shallow foundations to lateral movements with an associated vertical component (not to scale).

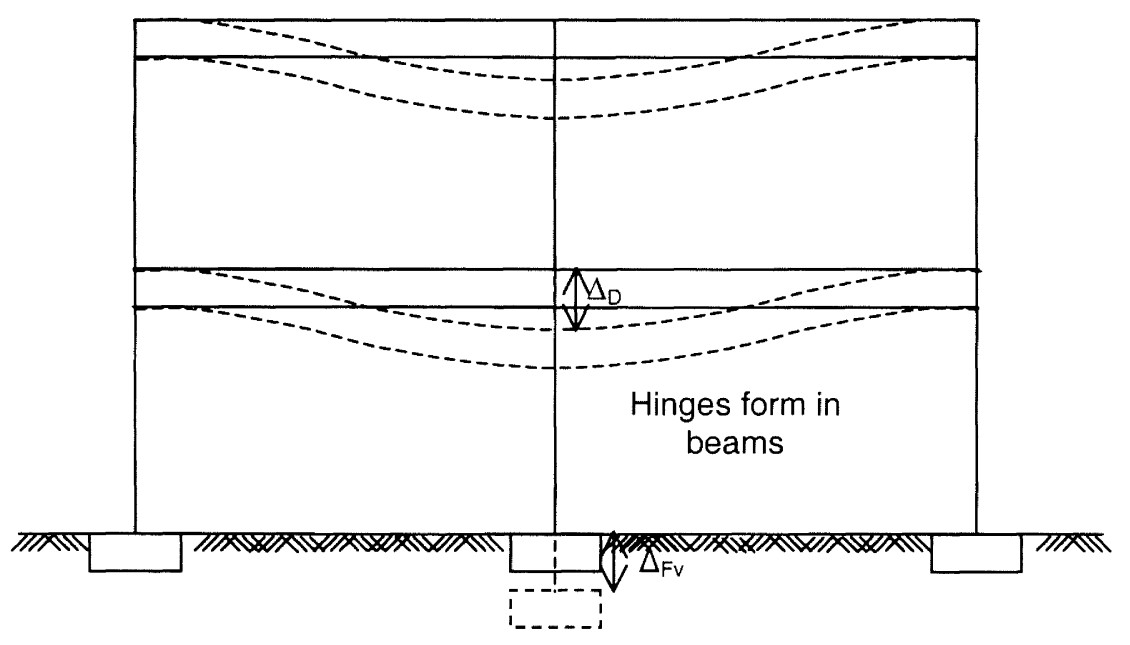

Figure 5: Idealised response of a multi-bay RC frame building to differential settlements beneath an internal column (not to scale).

Where the demand also comprises horizontal ground displacements, the failure mechanism is again concentrated in the ground floor columns (Fig. 4), since the axial stiffness of the beams is much higher than the flexural stiffness of the columns. Two potential scenarios involving horizontal ground deformation were considered, either with or without a vertical component. Parametric studies were again undertaken using the structural models and these showed that only a very small vertical component is required to cause the deformation mode shown in Fig. 4. In practice there would 
almost always be a vertical component to lateral spreading therefore only this deformation mode has been considered Although the presence of a vertical component was found to influence the deformed shape of the structure, the amplitude of the horizontal foundation deformation was found to govern the damage state: i.e., given that vertical ground deformation occurs, and making the reasonable assumption that it will be less than the horizontal component, its actual amplitude is not required. This finding is compatible with the fact that most assessment methodologies tend to consider only the horizontal component (with the exception of Shamoto et al., 1998), and therefore the vertical component of lateral spreading (as opposed to simple volumetric strain in level ground) is less easily predicted. However, it is also noted that this simplification of lateral spreading to a horizontal component only may lead to over-estimates of the movement, as shown by Çetin et al. (2002).

\subsection{Building damage}

Existing methods for the assessment of building damage due to ground displacement mostly relate to damage caused by either long-term consolidation settlement (e.g. Burland and Wroth, 1975) or movements induced by excavation or tunnelling (e.g. Boscardin and Cording, 1989). Such methods typically fall into one of two groups: those using empirical data from case histories to determine allowable settlement limits (e.g. Skempton and McDonald, 1956) or methods which apply structural engineering principles. Those presented by Burland and Wroth (1975), who modelled building walls as simply supported beams, considering deformation modes and critical tensile strains fall into the latter category. In the context of earthquake-induced liquefaction, which may affect a significant percentage of the building stock in a region, and which may generate differential ground movements of an order of magnitude greater than those considered by the aforementioned authors, these methodologies provide some useful background, but have only limited applicability. For example, at Moss Landing, differential settlements of $0.35 \mathrm{~m}$ were observed across a relatively small structure, after the 1989 Loma Prieta earthquake (Boulanger et al., 1995).

The procedure presented in this paper has some distinct advantages, particularly in the context of large regional ground displacements caused by earthquake-induced liquefaction. The formulae for assessment of the capacity of buildings to resist such displacements, presented in the following section, are derived from sound mechanical principles, using simple geometric and material variables. The resulting building damage states are directly obtained from the calculations, and neither judgement nor empirical data are required to define the damage distribution.

Table 1: Structural damage state descriptions for RC frame buildings (adapted from HAZUS, FEMA ${ }^{10}$ by Crowley et al. ${ }^{13}$ )

\section{Structural Damage Band Description}

\begin{tabular}{cl}
\hline \multirow{2}{*}{ None to Slight } & $\begin{array}{l}\text { Linear elastic response, flexural or shear type hairline } \\
\text { cracks }(<1.0 \mathrm{~mm}) \text { in some members, no yielding in } \\
\text { any critical section. }\end{array}$ \\
\hline \multirow{3}{*}{ Moderate } & $\begin{array}{l}\text { Member flexural strengths achieved, limited ductility } \\
\text { developed, crack widths reach } 1.0 \mathrm{~mm}, \text { initiation of } \\
\text { concrete spalling. }\end{array}$ \\
\hline \multirow{2}{*}{ Extensive } & Significant repair required to building, wide flexural \\
& or shear cracks, buckling of longitudinal \\
& reinforcement may occur. \\
& Repair of building not feasible either physically or \\
economically, demolition after earthquake required, \\
could be due to shear failure of vertical elements or \\
excess displacement
\end{tabular}


Damage to buildings or infrastructure can be quantified on a continuous scale from zero (no damage) to unity (collapse) where values relate to the ratio of damage repair to total rebuilding costs. For expedience, damage levels are grouped into the following ranges, or damage states: slight, moderate, extensive and complete (e.g. FEMA, 2003), which can then be qualitatively described. A descriptive definition of the damage state is important so that from the end results there can be an understanding of the nature and extent of the predicted damage (Whitman et al., 1997). Descriptions of structural damage states of RC frame buildings are given in Table 1.

\section{ANALYTICAL SOLUTIONS TO DAMAGE CAUSED BY DIFFERENTIAL FOUNDATION MOVEMENTS}

An analogy between a displacement applied at foundation level and lateral displacement-based assessment procedures now commonly used in earthquake resistant design and assessment (e.g. Priestley, 1997) forms the basis of these solutions. Using the principles of displacement-based assessment, semi-empirical and semi-mechanical formulations have been derived for the capacity of a frame to resist lateral drift, and it has been found, as shown below, that these formulae are easily adaptable to the case of applied foundation displacements. A singular advantage of these relationships is that they are fully compatible with the seismic vulnerability assessment methodology developed by Crowley et al. (2004), using the same geometric and material properties as variables, the same limit state definitions, and the same probabilistic framework.

As described in Section 2.3, differential movement of the ground beneath a building with unrestrained or compliant foundations will cause deformation of the beams or columns. The damage state will therefore be controlled by the capacity of the beams or columns to resist this deformational demand, and can be determined analytically, through the use of simplified relationships for the displacement capacity, as will be described subsequently. The key features of the approach as presented in this paper are:

- Only bare reinforced concrete frame buildings are considered; the contribution of even unreinforced masonry infill walls to building capacity is likely to mean that this simplification leads to somewhat overconservative results.

- The demand due to ground failure is specified in terms of the differential vertical and/or horizontal movements.

- Non-structural damage states are not included, although damage to non-structural elements such as partition walls or external cladding, can be estimated in a similar manner, since damage to such elements will be related to the deflection of the connecting beams and columns (e.g. Crowley et al., 2004)

- Only representative cases of regular buildings are presented. There are a number of combinations of localised ground deformations and building configurations, that will cause different responses. However, the cases presented are considered representative of general behaviour.

- The foundation deformation is assumed to be equal to the free-field deformation of the soil. For small- to medium-sized structures, this is considered reasonable, but if anything will result in slightly conservative predictions of damage (Boscardin and Cording, 1989)

The formulae presented below have been adapted from the displacement-based vulnerability assessment procedure for earthquake loss estimations, initially proposed by Pinho et al. (2002) and subsequently developed in a deterministic framework by Glaister and Pinho (2003); Crowley et al. (2004) refined the approach for reinforced concrete momentresisting frames and extended it into a fully probabilistic framework. The central tenet of the methodology is that a relationship between displacement capacity and period of vibration can be used to define limit states for any building class (with similar material and geometric properties) and this can then be directly related to the ground-motion demand in terms of a displacement response spectrum. The uncertainty in both demand and capacity are treated probabilistically such that the final damage state definition includes the uncertainty related to the building period, building displacement capacity and ground-motion demand. Herein the methodology has been extended to cases where the demand is caused by an inter-column deformation at ground floor level as shown in Figs. 2 to 5 . 
In each case, the limit states are defined in terms of the yield capacity (LS1), which defines the boundary between slight and moderate damage. The second and third limit states (LS2 and LS3), which define the boundaries between moderate and extensive and between extensive and complete damage states, respectively, are both post-yield states, defined by limiting strains in the steel and concrete (Crowley et al., 2004). As discussed in Section 2.2, the building height and in turn the building period are not critical in assessing building response due to ground failure, although the storey height is a significant variable, as will be shown below.

\subsection{Vertical differential ground movement \\ 3.1.I Deformational demand to columns due to vertical ground movement}

In Fig. 2, the most likely deformation scenario leads to approximately equal differential deformation between bays and so a single frame may be studied alone, as presented in Fig. 3. The critical column in the aforementioned figure is the one to the left which undergoes the smaller displacement at ground level. Although it is simpler to describe this footing as stationary, with all of the ground movement taking place beneath the right-hand footing, this need not be the case in reality, since it is the differential movement of the footings that causes this mode of damage. Given that the beam rotates rigidly, the demand on this ground floor column is defined by the horizontal displacement, $\Delta_{D}$, at the top of the column, which can be obtained from simple geometry, as follows:

$$
\Delta_{D}=\frac{\Delta_{F V} h_{s}}{\sqrt{\left(l_{b}{ }^{2}-\Delta_{F V}{ }^{2}\right)}} \approx \frac{\Delta_{F V} h_{s}}{l_{b}}
$$

where, $\Delta_{l \cdot V}$ is the maximum differential vertical deformation of the foundation, $h_{s}$ is the storey height and $l_{b}$ is the beam length.

\subsubsection{Deformational capacity of critical column}

The critical column in the frame, described above, is assumed to behave as a cantilever in simple bending. The behaviour of a cantilever when subjected to a lateral deformation is illustrated in Figs. 6 and 7.
A typical cross section of a column is shown in Fig. 6 a and the strain profile at that section is shown in Fig. 6b. At any cross section, the curvature can be computed by the sum of steel and concrete strains ( $\varepsilon_{\mathrm{s}}$ and $\varepsilon_{\mathrm{c}}$, respectively) at the two extremes of the section, divided by the effective depth, $d$ '. The column member is presented in Fig. 7a, with a height $h_{s}$ corresponding to that of the storey. When the section at the base of the column reaches the yield curvature, $\phi_{y}$, the first limit state is reached and the curvature distribution with height can be conservatively approximated as triangular (Fig. 7b). By integrating the curvature distribution along the length of the deformed member, the tangent yield rotation in Fig. $7 \mathrm{~d}, \theta_{t}$, is obtained and the yield displacement at the top of the column can be computed by the moment-area method.

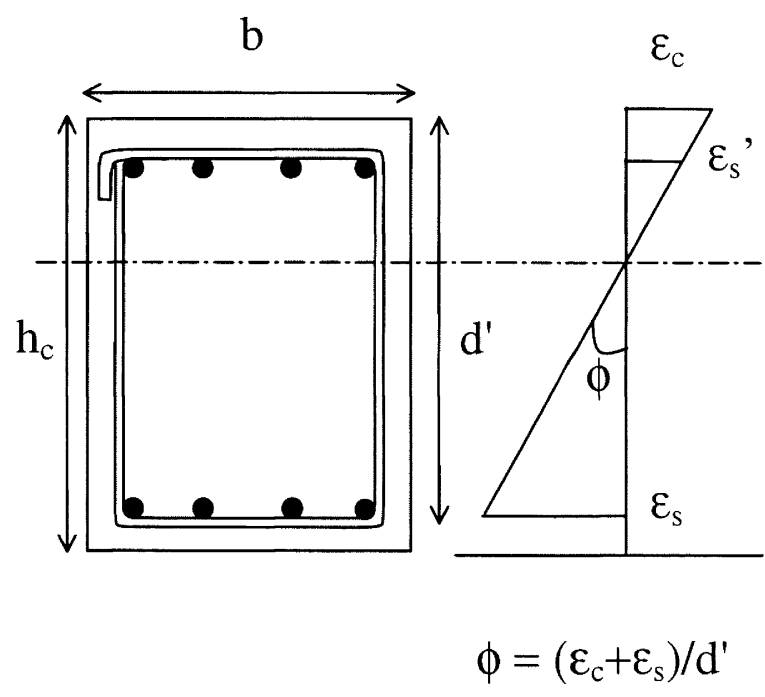

a)

b)

Figure 6: (a) typical poorly-confined reinforced concrete column section, (b) strain profile and definition of curvature. 


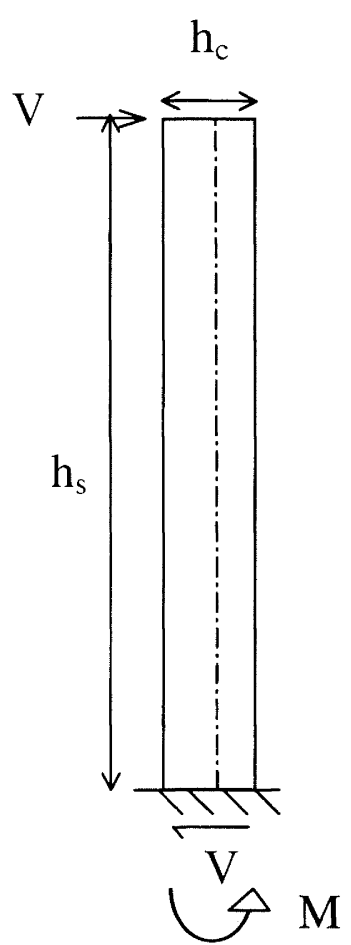

a)

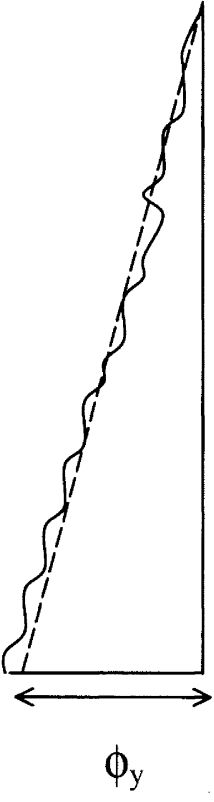

b)

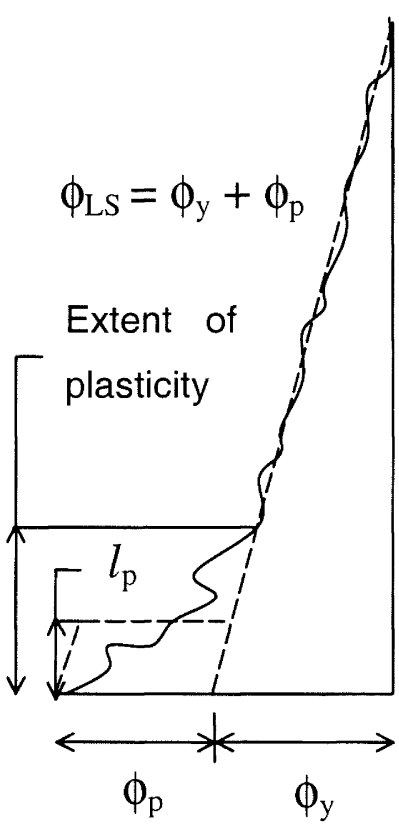

c)

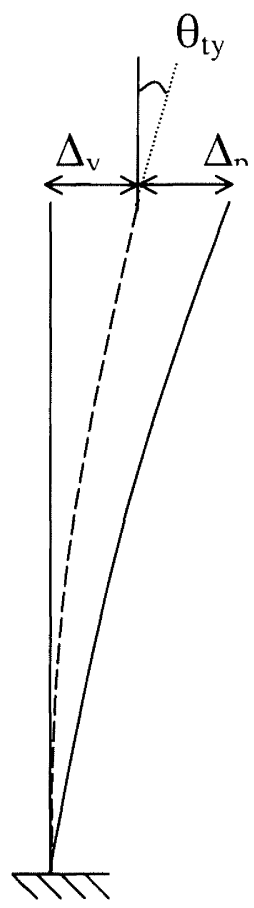

d)

Figure 7: (a) prismatic reinforced concrete cantilever, (b) curvature distribution with height when the section at base reaches yield curvature (limit state 1), (c) curvature distribution with height at post-yield limit states, (d) components of total lateral tip deflection (Not to scale; adapted from Paulay and Priestley, 1992).

An estimate of the yield curvature of a column, which is given in terms of geometric and material properties of the reinforced concrete section is obtained from Priestley (2003):

$$
\phi_{y}=\frac{2.14 \varepsilon_{y}}{h_{r}}
$$

The tangent yield rotation at the top of the column, $\theta_{t y}$, shown in Fig. 7 d, is calculated by integrating the curvature distribution at yield (Eq. 3) and then this is increased using empirical factors proposed by Priestley (2003) to account for shear and joint deformations (Eq. 4).

$$
\theta_{t y^{\prime}}=\phi_{y} \frac{h_{s}}{2}=1.07 \varepsilon_{y^{\prime}} \frac{h_{s}}{h_{c}}
$$

$$
\theta_{y}=1.35 \theta_{y}=1.44 \varepsilon_{y} \frac{h_{s}}{h_{c}}
$$


The moment-area method is then used to find the yield displacement capacity, $\Delta_{y}$, at the top of the column:

$$
\Delta_{y}=\theta_{y} \frac{2}{3} h_{s}=0.96 \varepsilon_{y} \frac{h_{s}{ }^{2}}{h_{c}}
$$

The curvature distribution of the column at the post-yield limit states is presented in Fig. $7 \mathrm{c}$. The plastic curvature, $\phi_{p}$, can be found from the difference between the limit state curvature, $\phi_{t S S}$, and the yield curvature at the base of the section, as shown below:

$$
\begin{aligned}
& \phi_{p}=\phi_{L S}-\phi_{y}=\left(\varepsilon_{c L S}+\varepsilon_{s L S}\right) \frac{1}{h_{c}}-\frac{2.14 \varepsilon_{y}}{h_{c}} \\
& =\left(\varepsilon_{c L S}+\varepsilon_{s L S}-2.14 \varepsilon_{y}\right) \frac{1}{h_{c}}
\end{aligned}
$$

The limit state curvature has been approximated by the sum of the limit state steel and concrete strains at the two extremes of the section ( $\varepsilon_{s L S S}$ and $\varepsilon_{C L L S}$, respectively), divided by the total depth of the column section. The dotted lines in Fig. $7 \mathrm{c}$ show the approximate curvature distribution that has been assumed in order to simplify the integration of the actual curvature profile. In this way, the plastic curvature may be multiplied by a plastic hinge length, $l_{p}$, assumed to be half of the section depth (see Paulay and Priestley, 1992), to give the plastic rotation capacity:

$$
\begin{aligned}
& \theta_{p}=\phi_{p} l_{p}=\phi_{p} \cdot 0.5 h_{c} \\
& =\left(\varepsilon_{c L S}+\varepsilon_{s L S}-2.14 \varepsilon_{y}\right) 0.5
\end{aligned}
$$

As can be noted from Fig. 7c, the plastic hinge length does not represent the total extent of plasticity, but may be considered to be a representative length used for computational purposes. The plastic displacement at the tip of the cantilever shown in Fig. $7 \mathrm{~d}$ is then found by multiplying the plastic rotation by the height of the column:

$$
\Delta_{P}=\theta_{p} h_{s}=\left(\varepsilon_{c L S}+\varepsilon_{s L S}-2.14 \varepsilon_{y}\right) 0.5 h_{s}
$$

The total limit state displacement capacity given in Eq. 9 is finally obtained by adding the yield displacement, from Eq. 5 , to the plastic displacement.

$$
\begin{aligned}
& \Delta_{L S}=\Delta_{y}+\Delta_{p}=0.96 \varepsilon_{y} \frac{h_{s}^{2}}{h_{c}} \\
& +\left(\varepsilon_{c L S}+\varepsilon_{s L S}-2.14 \varepsilon_{y}\right) 0.5 h_{s}
\end{aligned}
$$

In summary, Eq. 1 is used to define the demand at the top of the ground floor column due to foundation settlement, and the capacity at this level is defined by Eq. 5 for Limit State 1 (yield) and Eq. 9 for Limit States 2 and 3 (post-yield), where the two post-yield states are distinguished by the specified allowable concrete and steel strains. A building's ultimate damage state due to the ground deformation will be defined by which limit states it exceeds.

\subsection{Vertical ground deformations at the centre of a multi-bay frame}

\subsubsection{Deformational demand to beams due to vertical} ground movement

For the case where the vertical differential settlement beneath a building occurs solely beneath an internal column (Fig. 5), or alternatively, the two outer columns settle more than the central column, the response of the frame will be different, since the lack of freedom for lateral movement of the outer columns causes the columns to remain vertical and the deformations to take place in the beams rather than the columns. Unlike for the multi- or single-bayed cases in Figs. 2 and 3, the upper storeys will also be damaged in this case, since the beam rotation must occur at every level. The vertical displacement demand on the beam, $\Delta_{l}$, is given by the vertical ground deformation, $\Delta_{F v}$

\subsubsection{Deformational capacity of beams}

The displaced shape of each beam due to the deformational demand described in the previous section is shown in Fig. 8; this type of deformation is termed double bending. The behaviour may be likened to that presented previously for a cantilever in Fig. 3, but in this case there are two cantilevers each of length $l_{b} / 2$, rotated by $90^{\circ}$ and placed end to end, 
leading to a point of contraflexure at the centre of the beam. Plastic hinges are assumed to form at either end of the beam.

Again, the yield curvature of the beam may be defined in terms of the geometric and material properties of the member using the relationships derived by Priestley (1998):

$$
\phi_{y}=\frac{1.7 \varepsilon_{y}}{h_{b}}
$$

The yield chord rotation, $\theta_{y}$, of the beam shown in Fig. 8 (the angle between the tangent to the axis at the yielding end and the point of contraflexure) can be found from the curvature distribution of Fig. $7 \mathrm{~b}$; however, it should be noted that this curvature represents the distribution along only half the length of the beam. The moment area method can be used to calculate the displacement at the centre of the beam, as carried out previously for the column, and this is then divided by half the length of the beam to give the chord rotation:
In reality, in a reinforced concrete section, shear and joint deformations occur in addition to the flexural deformation of the beam and so the yield chord rotation may be increased using the following empirical factors proposed by Priestley (2003):

$$
\theta_{y}=1.35 \theta_{t y}=0.382 \varepsilon_{y} \frac{l_{b}}{h_{b}}
$$

For small rotations, the chord rotation, $\theta_{y}$, can be multiplied by the length of the beam, $l_{b}$, (Eq. 13) to give the vertical displacement capacity of the beam, $\Delta_{y}$, as is schematically shown in Fig. 8.

$$
\Delta_{y}=\theta_{y} l_{b}=0.382 \varepsilon_{y} \frac{l_{b}^{2}}{h_{b}}
$$

$$
\begin{aligned}
& \theta_{t y}=\frac{1}{l_{b} / 2}\left(\frac{\phi_{y}}{2} \cdot \frac{l_{b}}{2} \cdot \frac{2}{3} \cdot \frac{l_{b}}{2}\right) \\
& =\phi_{y} \frac{l_{b}}{6}=0.283 \varepsilon_{y} \frac{l_{b}}{h_{b}}
\end{aligned}
$$

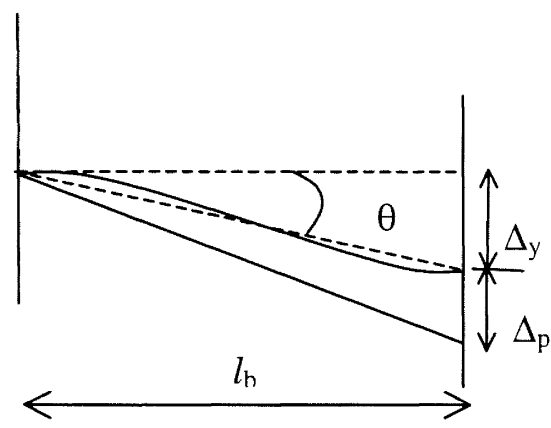

Figure 8: Displaced shape of beam due to vertical ground deformations at the centre of a multi-bay frame.

The plastic curvature distribution of Fig. 7c may also be used in the case of a beam in double bending, considering again that this figure would only represent half of the beam. The same procedure discussed in Section 3.1.2 is thus applied, where the limit state plastic curvature is found from Eq. (14) and the plastic rotation (Eq. 15) is given by the plastic 
curvature multiplied by the plastic hinge length (this is again taken as half of the section depth).

$$
\begin{aligned}
& \phi_{p}=\phi_{L S}-\phi_{y}=\left(\varepsilon_{c L S}+\varepsilon_{s L S}\right) \frac{1}{h_{b}}-\frac{1.7 \varepsilon_{y}}{h_{b}} \\
& =\left(\varepsilon_{c L S}+\varepsilon_{s L S}-1.7 \varepsilon_{y}\right) \frac{1}{h_{b}} \\
& \theta_{p}=\phi_{p} l_{p}=\phi_{p} \cdot 0.5 h_{b} \\
& =\left(\varepsilon_{c}+\varepsilon_{s}-1.7 \varepsilon_{y}\right) 0.5
\end{aligned}
$$

The plastic displacement shown schematically in Fig. 8 is found by multiplying the plastic rotation by the length of the beam (Eq. 16) and this is added to the yield displacement to give the limit state displacement capacity (Eq. 17).

$$
\Delta_{P}=\theta_{p} l_{b}=\left(\varepsilon_{c L S}+\varepsilon_{s L S}-1.7 \varepsilon_{y}\right) 0.5 l_{b}
$$

$$
\begin{aligned}
& \Delta_{L S}=\Delta_{y}+\Delta_{p} \\
& =0.382 \varepsilon_{y} \frac{l_{b}^{2}}{h_{b}}+\left(\varepsilon_{c L S}+\varepsilon_{s L S}-1.7 \varepsilon_{y}\right) 0.5 l_{b}
\end{aligned}
$$

\subsection{Horizontal differential ground deformations}

3.3.1 Deformational demand due to horizontal ground movement

The deformed shape of a building subjected to a horizontal ground deformation caused by lateral spreading is shown in Fig. 4. As noted in Section 2.1, it is assumed, with reason, that there is always a vertical component to lateral ground movements, which will generally be smaller than the horizontal component. The amplitude of the vertical component, however, is not needed, since the amplitude of the horizontal foundation deformation, $\Delta_{F H}$, governs the damage state.
The mode of deformation in this case is similar to that in Fig. 3 , for vertical deformations only. The differential settlement of the right-hand column in Fig. 4 causes a redistribution of loads, such that the load on the left-hand column is reduced. The demand on the critical left-hand column, $\Delta_{l}$, shown in Fig. 4, can be approximated as the maximum differential horizontal deformation of the foundation, $\Delta_{F I I}$, i.e.:

$$
\Delta_{D} \approx \Delta_{F H}
$$

\subsubsection{Deformational capacity of critical column}

The critical column of a frame subjected to horizontal ground movement is assumed to behave though a combination of simple and double bending, as illustrated in Fig. 9. Thus, a combination of the results presented in Section 3.1.2 for simple bending and Section 3.2.2 for double bending, adapted for a column section, is used to derive equations for the displacement capacity of the critical column.

The yield rotation capacity of a column under simple bending has been presented in Eq. 4, and that of double bending has been illustrated for a beam in Fig. 8 and presented in Eq. 12. For a column, the yield chord rotation capacity under double bending, accounting also for shear and joint deformations, can be defined by the following equation:

$$
\theta_{y}=0.382 \varepsilon_{y} \frac{h_{s}}{h_{c}}
$$

The chord rotation of a cantilever can be obtained by dividing Eq. 5 by the height of the storey, as follows:

$$
\theta_{y}=0.96 \varepsilon_{y} \frac{h_{s}^{2}}{h_{c}} \cdot \frac{1}{h_{s}}=0.96 \varepsilon_{y} \frac{h_{s}^{2}}{h_{c}}
$$




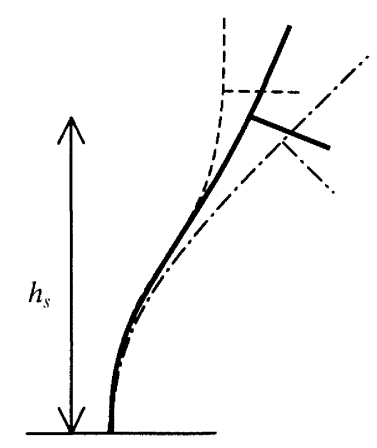

Figure 9: Displaced shape of column due to horizontal differential ground deformation (bold line), schematically shown to be a combination of simple bending (dot-dashed line) and double bending (dotted line).

The average of the two chord rotation capacities for simple and double bending is therefore used to provide a simple representation of the combination of these two deformation profiles:

$$
\theta_{y}=\frac{0.96+0.382}{2} \varepsilon_{y} \frac{h_{s}}{h_{c}}=0.67 \varepsilon_{y} \frac{h_{s}}{h_{c}}
$$

Hence, following the procedure outlined previously of multiplying the chord rotation by the length of the element, the horizontal yield displacement capacity of the column is:

$$
\Delta_{y}=0.67 \varepsilon_{y} \frac{h_{s}{ }^{2}}{h_{r}}
$$

It is worth noting here that the plastic rotation is the same regardless of whether the column is in simple or double bending. As has been mentioned previously, a member in double bending might be thought of as two members in simple bending, placed end to end. Thus, the plastic displacement of a cantilever of height $h_{s}$ is the same as the plastic displacement of two combined cantilevers, each with height $h_{s} / 2$, such as occurs in a column of height $h_{s}$ in double bending. In the post-yield limit state, the plastic rotational capacity of the column is thus calculated from the plastic curvature and multiplied by the plastic hinge length of the section, as has been previously shown for the cantilever in Eqs. 6 and 7. The plastic displacement is then found by multiplying the plastic rotation by the height of the column (Eq. 8) and this is added to the yield displacement (Eq. 21), leading to the post-yield displacement capacity of the critical column under horizontal differential ground deformations:

$$
\Delta_{L S}=0.67 \varepsilon_{y} \frac{h_{s}^{2}}{h_{c}}+\left(\varepsilon_{c}+\varepsilon_{s}-2.14 \varepsilon_{y}\right) 0.5 h_{s}
$$

\section{APPLICATION OF THE ANALYTICAL PROCEDURES TO EARTHQUAKE LOSS MODELS
4.1 Probabilistic framework for the damage estimation

Application of Eqs. 1 to 23 allow direct evaluation of the damage state of any building class, defined by its geometric and material properties, when subject to a ground deformation defined in terms of its horizontal and vertical components. The damage states are determined as a function of the yield strain of steel and post-yield strains in the steel and concrete. However, such a calculation is strictly deterministic, and it is recognised that there are significant uncertainties related to both the capacity and the demand and that therefore a probabilistic framework is preferable (Crowley et al., 2004). For the analysis of building vulnerability due to ground shaking, where both the period and the capacity of the building class are significant variables, with separate and independent uncertainties, a joint 
probability density function (JPDF) is required to fully model the variability of the capacity.

In the case of ground deformations, since the period is not a significant variable, a single PDF can be used to describe the uncertainty in the displacement capacity, which is a function of the material properties, geometric properties, and the yield strain of steel and post-yield strain capacities of the steel and concrete (see, for example, Eq. 5 which presents the yield displacement capacity of a column). Each of the aforementioned parameters are assigned appropriate probability distributions and variances, which are combined to obtain the overall PDF of the capacity $\left(f_{c}\right)$ using the first order reliability method (FORM) (e.g. Pinto et al., 2004) for each group of buildings with similar properties.

For the analysis of vulnerability due to ground shaking, the uncertainty in the demand can be represented by the commonly accepted assumption of a log-normal distribution of the scatter associated with the ground-motion prediction relationship. For the case of ground deformation, the uncertainty in the demand (for example, $\Delta_{F v}$ in Fig. 4) includes all of the variability associated with ground motion estimation plus the additional uncertainties associated with the triggering of liquefaction, the variability in soil parameters and stratigraphy and the uncertainty within the assessment in ground deformations. The final requirement of the methodology is that all of these uncertainties be combined in order to obtain a single cumulative distribution function (CDF) representing the demand $\left(F_{D}\right)$.

Having defined the PDF of the limit state displacement capacity $\left(f_{c^{\prime}}\right)$ and the CDF of the displacement demand $\left(F_{D}\right)$, the probability of exceeding a given limit state $\left(P_{f L S}\right)$ is given by the reliability formula:

$$
P_{f L S}=\int\left[1-F_{D}(x)\right] f_{C}(x) d x
$$

In order to estimate losses in a zone susceptible to ground failure, it is necessary to define the probability of liquefaction being triggered for the scenario earthquake, the relative likelihood of uniform, differential vertical or differential lateral ground deformations, and for each of these a probability distribution to describe the amplitude and range of movement. The methodology described in this paper is for one branch of the subsequent calculations, where foundations are flexible. A similar framework needs to be followed for buildings on stiff or piled foundations in order to obtain damage distributions for each building category within the ground failure zone. The evaluation of the average expected liquefaction-induced displacements and their variation over the study area is far from straightforward since a number of different methodologies are available, all of which use different approaches and different uncertain variables, none of which have overwhelming support in their favour compared to the others. Many commonly used assessments rely heavily on empirical data, one reason for this being the difficulty in obtaining measured in situ soil properties for input to soil mechanics theory and the variability associated with such properties (Glaser, 1994) For the purpose of loss estimations, empirically-based procedures, based upon easily obtainable parameters, or at least parameters that can be estimated using a reasonable level of judgement, are preferable to complex numerical approaches, which can be very sensitive to uncertainties (Seed et al., 2003).

\subsection{Vulnerability curves}

From the relationships defined in Section 3.1 to 3.3 , it is straightforward to derive vulnerability curves of the differential permanent ground deformation, $\Delta_{F V}$ and $\Delta_{F I}$, versus the probability of exceedance of the three limit states. In the curves presented in Figs. 10 and 11, the probability distribution is due to the variability in the capacity only, since the demand is modelled deterministically. The mean values of storey height and beam length are $3.5 \mathrm{~m}$ and $4.0 \mathrm{~m}$ respectively and the building class is assumed to be poor quality such that structural members are inadequately confined. Preliminary coefficients of variation for all of the input parameters are discussed by Crowley et al. (2004), and the same values are adopted herein.

Since these curves are for a specific combination of geometry, material properties and limit states, it is important to note that they are presented for illustrative purposes only. The curves show the probability of exceeding each of the three limit states with respect to the demand, which is a function of the earthquake intensity and the extent and variability of liquefiable soil beneath the foundation. 


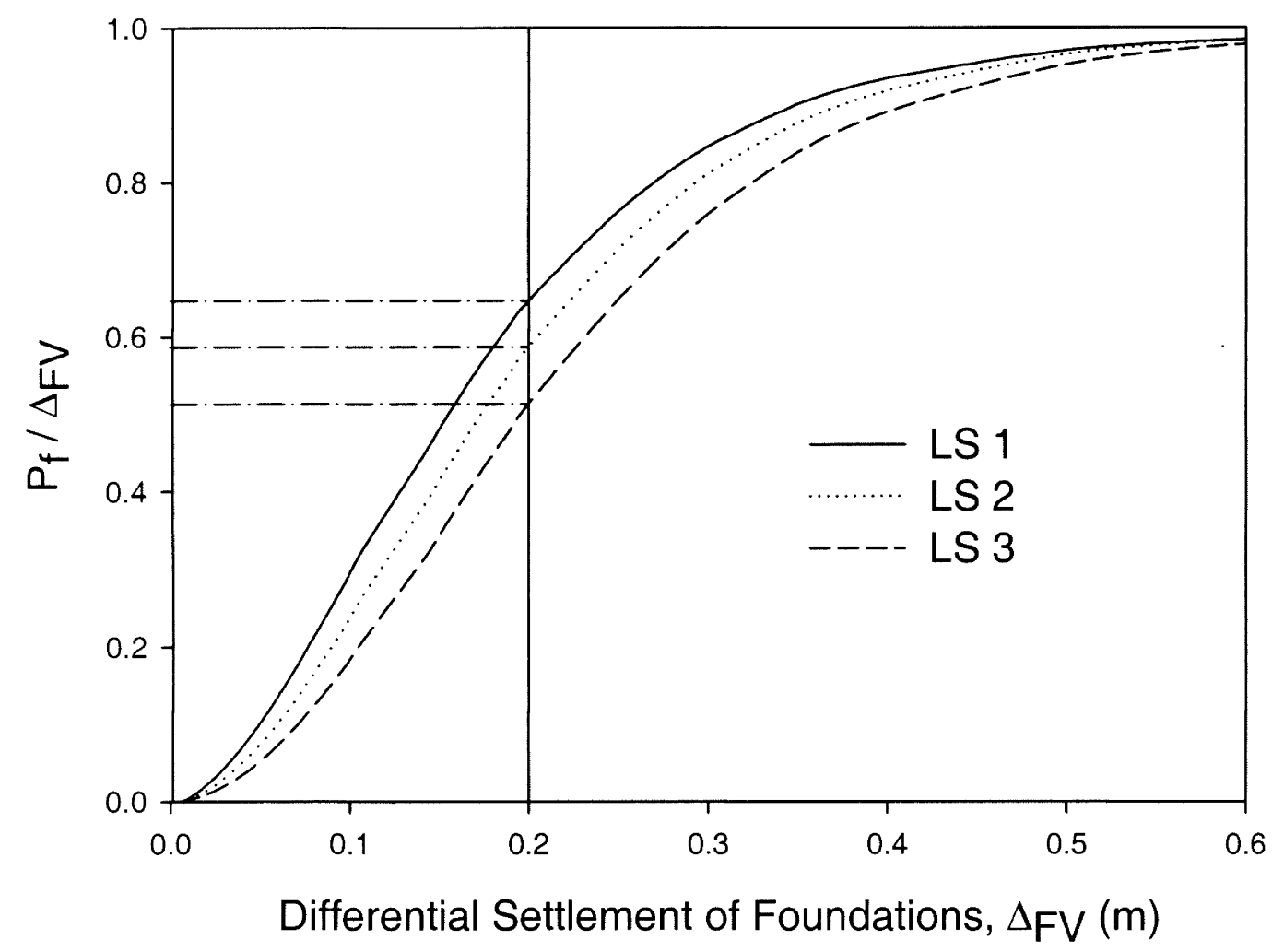

Figure 10: Illustrative vulnerability curves for multi- and single-bay, poor quality, RC frame buildings characteristic of European building stock, subjected to differential vertical settlement (as shown in Figure 3).

The vertical line on Fig. 10 shows that for buildings subjected to $\Delta_{l \cdot V}=200 \mathrm{~mm}$, a single building would have a $35 \%$ probability of experiencing slight damage, a $6 \%$ probability of moderate damage, an $8 \%$ probability of extensive damage and a $51 \%$ probability of complete damage.

The curves for the three limit states are very close together in Fig. 10. The physical significance of this is when the section has yielded (i.e. failed LS1), the inadequate confinement that is assumed for a poor building means that it will very rapidly also fail the second and third limit states due to the low levels of attainable limit state strains. For a good building, there is greater separation between the curves, representing the greater post-yield capacity due to the higher limit state strains of adequately confined members. Possible mean values for post-yield limit state strains for concrete and steel are presented in Table 2 for both poorly confined (poor) and well confined (good) buildings. However, it should be noted that high coefficients of variation (around 50\%) are associated with such values (Crowley et al., 2004).

The curves in Figs. 10 and 11 are very useful for consideration of the probabilistic treatment of structural response to foundation movements, although it should be remembered that they represent a simplified case in that the demand is treated deterministically, i.e. it is assumed to have a single value with no variability. 


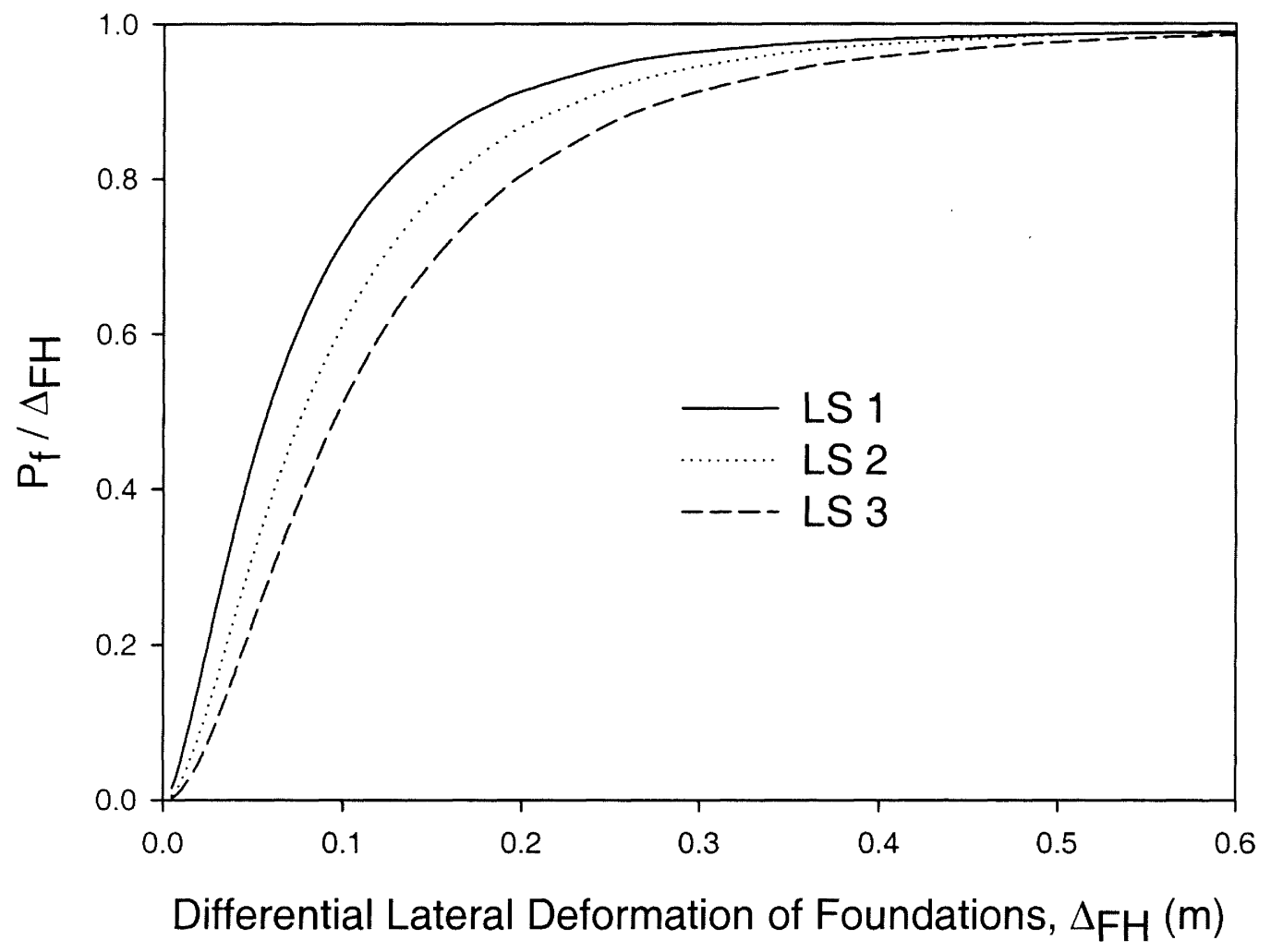

Figure 11: Vulnerability curves for poor quality, RC frame buildings subjected to differential horizontal foundation deformations (as shown in Figure 4).

Table 2: Mean post-yield limit state strains suggested for steel $\left(\varepsilon_{\mathrm{s}}\right)$ and concrete $\left(\varepsilon_{\mathrm{c}}\right)$ for poorly confined (poor) and well confined (good) buildings.

\begin{tabular}{ccccc}
\hline \multirow{2}{*}{ Limit state } & \multicolumn{2}{c}{ Poor Buildings } & \multicolumn{2}{c}{ Good Buildings } \\
\cline { 2 - 5 } & $\varepsilon_{\mathrm{s}}$ & $\boldsymbol{\varepsilon}_{\mathrm{c}}$ & $\boldsymbol{\varepsilon}_{\mathrm{s}}$ & $\boldsymbol{\varepsilon}_{\mathrm{c}}$ \\
\hline 2 & 0.0125 & 0.0045 & 0.0125 & 0.0045 \\
3 & 0.0225 & 0.0075 & 0.0500 & 0.0150 \\
\hline
\end{tabular}

In the assessment of damage caused by ground shaking (Crowley et al., 2004) the poor and good building classes may be defined by their expected failure mechanism, where poorly designed buildings are more likely to suffer softstorey (column-sway) failures, as well as reduced limiting steel and concrete strains due to lack of confinement. For the damage due to ground deformation only, the susceptibility or not to column-sway failures is not significant; therefore the difference between the vulnerability of poor and good buildings is due only to confinement levels, and the subsequent limiting strains assigned to each limit state. If alternative assumptions were to be made about the foundation system for a well-designed building, for example that the foundations would be either deep or else stiff shallow rafts, then this difference could be significantly greater.

\section{CONCLUSIONS}

In this paper, a framework has been presented for estimating the damage caused to a given building class as a result of 
ground deformations resulting from earthquake-induced liquefaction. Methods for the identification of liquefaction susceptibility and the potential for the initiation of liquefaction under a given level of shaking continue to be developed and refined, but without the capability to determine what this means for the affected infrastructure the usefulness of such methods is inevitably limited. The framework presented in this paper seeks to address this shortcoming, through the development of a set of relationships for the capacity of a building subjected to ground deformations. In addition to its intended application, the methodology is equally suitable to any other cause of widespread ground deformations that require an estimation of the expected building damage distribution, presented in terms of the final damage state in which buildings end up.

A series of analytical relationships have been presented for the case of reinforced concrete frame structures with relatively flexible foundations such as pad footings. The methodology presented has been developed for regional earthquake loss estimations, and as such is particularly applicable to a large building stock, where buildings need to be grouped into classes with similar expected response to the earthquake demands, and represented using as few variable input parameters as possible, to facilitate data collection. The presented approach is only for one element of a loss estimation. For a complete coverage of liquefaction hazard, other branches are required to cover other building types, and other foundation systems, including relatively stiff foundations, which would lead to buildings responding essentially as rigid bodies. Further development of the methodology should also include calibration against field observations, although there is insufficient case history data to do this at present, and investigation into the sensitivity of the results to the uncertain variables related to both the building capacity (including the contribution of infill wall panels) and the permanent ground deformation demand.

A rational and realistic approach to the complex problem of soil-structure interaction in liquefied soil needs to consider all the uncertainties associated with the behaviour of the soil and of the structure, and how the two interact, on top of the ground-motion variability. The variability and uncertainty relating to the demand is a major issue, which has not been fully considered in this paper. The focus of this paper has been the probabilistic treatment of the capacity, and how to treat this in a systematic manner. The analytical solutions presented herein form one component of a generalised framework for including ground failure in earthquake loss estimation models, which incorporates other building classifications and modes of building response (Bird et al., 2006).

\section{ACKNOWLEDGEMENTS}

The work was carried out at the ROSE School, Pavia, Italy, where the first and second authors were funded through a Marie Curie fellowship from the European Commission, and the SAFERR Research Training Network from the European Community, respectively. Financial assistance for the first author's research at Imperial College London from the EPSRC and Arup is also gratefully acknowledged. The authors are very grateful for the constructive comments and suggestions of the anonymous reviewer, which improved the original manuscript. We are also grateful to others who provided useful feedback and insights throughout the development of this work, in particular Professor John Burland and Dr Dina D'Ayala.

\section{NOTATION}

$d^{\prime} \quad$ Effective column depth

$\mathrm{f}_{\mathrm{C}} \quad$ Probability Density Function (PDF) of capacity

$\mathrm{F}_{\mathrm{D}} \quad$ Cumulative Distribution Function (CDF) of demand

$\mathrm{F}_{\mathrm{L}} \quad$ Factor of Safety against liquefaction

FORM First Order Reliability Method

$h_{c} \quad$ depth of the column section

$h_{s} \quad$ storey height

$l_{b} \quad$ beam length

$l_{p} \quad$ plastic hinge length

LS1 Limit State 1 (yield)

LS2 Limit State 2 (post-yield)

LS3 Limit State 3 (post-yield)

$\mathrm{P}_{/ L S} \quad$ Probability of exceeding a given damage state

$\Delta_{\text {-Ls }} \quad$ post-yield limit state displacement capacity of member

$\Delta_{\mathrm{y}} \quad$ yield limit state displacement capacity of member

$\Delta_{\mathrm{D}} \quad$ displacement demand on beams or columns 
$\Delta_{\mathrm{FH}} \quad$ maximum differential horizontal deformation of the foundation

$\Delta_{\mathrm{FV}} \quad$ maximum differential vertical deformation of the foundation

$\Delta_{\mathrm{P}}$ plastic displacement capacity concrete strain

$\varepsilon_{c}$ $\varepsilon_{\mathrm{cLS}}$

$\varepsilon_{\mathrm{s}}$

\section{REFERENCES}

Bird, J.F., Bommer, J.J., Crowley, H., Pinho. R. (2006) "Modelling Liquefaction-Induced Building Damage in Earthquake Loss Estimation" Soil Dynamics and Earthquake Engineering, In Press.

Boscardin, M.D. and Cording, E.J. (1989) "Building response to excavation-induced settlement." $A S C E$ Journal of Geotechnical Engineering, 115(1).

Boulanger, R.W., Idriss, I.M. \& Mejia, L.H. (1995) "Investigation and evaluation of liquefaction related ground displacements at Moss Landing during the 1989 Loma Prieta earthquake" Report No. UCD/CGM-95/02, University of California at Davis.

Burland, J B. and Wroth, C. P. (1975) "Settlement of buildings and associated damage." Building Research Establishment, Garston, Eng., 1975, 44 pages, CP $33 / 75$.

Cetin, K.O., Youd, T.L., Seed, R.B., Bray, J.D., Dacio, R.B., Lettis, W., Yilmaz, M.T. and Durgunoglu, H.T. (2002) "Liquefaction-induced ground deformations at Hotel Sapanca during Kocaeli (Izmit), Turkey earthquake." Soil Dynamics and Earthquake Engineering, 22, 10831092.
Crowley, H., Pinho, R. and Bommer, J.J. (2004) "A probabilistic displacement-based vulnerability assessment procedure for earthquake loss estimation." Bulletin of Earthquake Engineering, 2(2), 173-219.

Eurocode 8: Design Provisions for earthquake resistance of structures. Part 5. Foundations, retaining structures and geotechnical aspects. DDENV 1998-5: 1996.

FEMA (2003) "HAZUS-MH Technical Manuals." Federal Emergency Management Agency, Washington, D.C.

Fenton, G.A. and Vanmarcke, H. (1998) "Spatial variation in liquefaction risk." Geotechnique, 48(6), 819-831.

Gere, P. and Timoshenko, S. (1997) "Mechanics of Materials" $4^{\text {th }}$ Edition, PWS Pub. Co., Boston.

Glaister, S. and Pinho, R. (2003) "Development of a simplified deformation-based method for seismic vulnerability assessment." Journal of Earthquake Engineering, 7(Special Issue 1), 107-140.

Glaser, S.D. (1994) "Estimation of surface displacements due to earthquake excitation of saturated sands." Earthquake Spectra, 10(3); 489-517.

Koutsourelakis, S., Prévost, J.H. and Deodatis, G. (2002) "Risk assessment of an interacting structure-soil system due to liquefaction." Earthquake Engineering and Structural Dynamics, 31, 851-879.

Paulay, T. and Priestley, M.J.N. (1992) "Seismic Design of Reinforced Concrete and Masonry Buildings", John Wiley and Sons, Inc, New York.

Pinho, R., Bommer, J.J. and Glaister, S. (2002) "A simplified approach to displacement-based earthquake loss estimation analysis" Proceedings of the 12th European Conference on Earthquake Engineering, London, England, Paper no. 738.

Pinto, P.E., Giannini, R. and Franchin, P. (2004) "Methods for seismic reliability analysis of structures." IUSS Press, Pavia, Italy.

Priestley, M.J.N. (1997) "Displacement-based seismic assessment of reinforced concrete buildings," Journal of Earthquake Engineering; 1(1): 157-192.

Priestley, M.J.N. (1998) "Displacement-based approaches to rational limit states design of new structures." Keynote 
Lecture, Proceedings of the $11^{\text {th }}$ European Conference on Earthquake Engineering, Paris, France.

Priestley, M.J.N. (2003) "Myths and fallacies in earthquake engineering - Revisited, Mallet-Milne Lecture", IUSS Press, Pavia, Italy.

Priestley, M.J.N. (2003) "Displacement-based seismic assessment of reinforced concrete buildings" Journal of Earthquake Engineering, 1(1), 157-192.

Seed, R.B., Cetin, K.O., Moss, R.E.S., Kammerer, A.M., Wu. J., Pestana, J.M., Reimer, M.F., Sancio, R.B., Bray, J.D., Kayen, R.E. \& Faris, A. (2003). "Recent advances in soil liquefaction engineering: a unified and consistent framework." 26th Annual ASCE Los Angeles Geotechnical Spring Seminar, Long Beach, California. Keynote Presentation.

SeismoSoft (2005) "SeismoStruct - A computer program for static and dynamic nonlinear analysis of framed structures" [online] Available from URL: http://www.seismosoft.com.

Skempton, A.W. and McDonald, D.H. (1956) "The allowable settlement of buildings." Proceedings of the Institution of Civil Engineers, London, 5, 3, 727-784.

Vanmarcke, H. (1977) "Probabilisitc modelling of soil profiles." ASCE Journal of Geotechnical Engineering, 103(GT11) 1277-1246.

Whitman, R.V., Anagnos, T., Kircher, C., Lagorio, H.J., Scott Lawson, R. \& Schneider. P. (1997) "Development of a national earthquake loss estimation methodology" Earthquake Spectra, 13 (4), 643-661. 